\title{
SEXUALIDADE E GÊNERO: PROCESSOS EMANCIPATÓRIOS NAS RELAÇÕES ENTRE UNIVERSIDADE E COMUNIDADE
}

\author{
Ana Paula Leivar Brancaleoni ${ }^{1}$ \\ Rosemary Rodrigues de Oliveira ${ }^{2}$
}

\begin{abstract}
RESUMO: O presente artigo apresenta e analisa a configuração de um projeto de Extensão Universitária, desenvolvido com Escolas Públicas, que tem por temas sexualidade e gênero. Busca-se compreender em que medida a mesmo favorece a manutenção do tripé ensino/pesquisa/extensão, enquanto promotor de aprendizados para a emancipação dos sujeitos envolvidos (graduandos, docentes e comunidade). Pautou-se nos pressupostos da pesquisa-ação, tendo como instrumentos de coleta de dados a análise documental e questionários respondidos por componentes do projeto do período de 2005 a 2011. Constatou-se que foram favorecidos processos formativos que rompem com visões estereotipadas, biologizantes e heteronormativas da sexualidade e do gênero, que predomina nos processos educacionais escolares. Além disso, favoreceu-se a vivência da indissociabilidade ensino/pesquisa/extensão, pautando-se na compreensão do conhecimento como algo construído nas e através das relações sociais.
\end{abstract}

Palavras-chave: Sexualidade; Gênero; Extensão Universitária; Processos Emancipatórios.

\begin{abstract}
This article presents and analyzes the configuration of a project of university extension, developed in partnership with public schools, which has as themes sexuality and gender issues. We seek to understand to which extent sexuality and gender issues contributes to the continuity of the trio teaching / research / extension, while acting as promoter of knowledge of emancipation of those envolved (under graduates, faculty and the community). We based our presuppositions on action research, with document analysis and questionnaires responded to by participants in the project during the period 2005 to 2011 as the instrument of data collection. We constituted that formative processes that disrupt the predominant perspectives in the educational processes of a stereotypical, biologizing and heteronormative nature of sexuality and gender issues were favoured. Moreover, the experience of inseparability of teaching/research/extension was favoured, based

\footnotetext{
1 Docente do Departamento de Economia Rural da Faculdade de Ciências Agrárias e Veterinárias Universidade Estadual Paulista "Júlio de Mesquita Filho" (UNESP) - Campus de Jaboticabal. Doutora em Psicologia pela Universidade de São Paulo (USP).

2 Docente da Faculdade de Ciências Agrárias e Veterinárias - Universidade Estadual Paulista "Júlio de Mesquita Filho" (UNESP) - Campus de Jaboticabal. Doutora em Educação para a Ciência pela Universidade Estadual Paulista "Júlio de Mesquita Filho" (UNESP) - Campus de Bauru.
} 
on the understanding of knowledge as something constructed in and through social relations.

Keywords: Sexuality; Gender Issues; University Extension; Processes of Emancipation.

\section{INTRODUÇÃO}

Ensino e aprendizagem compõem, de forma indissociável e não polarizada, o mesmo processo. Trata-se de algo complexo, vivo e marcado constantemente por desafios e enfrentamento de contradições.

Conforme prevê a concepção da Universidade brasileira, a mesma deve se sustentar por um tripé ensino/pesquisa/extensão, constituindo-se uma unidade, ou seja, apresentando um caráter intimamente imbricado.

Portanto, o espaço da extensão universitária deve ser fundamentalmente pensado enquanto um lugar de efetiva aprendizagem e construção de conhecimentos e não mera transmissão ou reprodução daquilo que se processou no ensino e/ou pesquisa. Não se trata de treino de habilidades profissionais e conhecimentos previamente definidos, mas íntima construção de novos saberes através da práxis (MARTINS, 2008). Mesmo porque a realização de tarefas, em si, não é promotora de desenvolvimento e transformação dos sujeitos (BLEGER, 1993). Como afirma Martins (2008):

Concordamos que a universidade deva retornar à sociedade o saber que dela se origina, mas numa busca incessante pela profunda compreensão da realidade social que a comporta; compreensão, apenas factível, pela mediação do pensamento abstrato construído e retroalimentado pelo ensino e pela pesquisa. Nesse sentido, a extensão ocupa lugar tão importante quanto o ensino e a pesquisa, pois é, sobretudo, por meio dela que os dados empíricos imediatos e teóricos se confrontam, gerando as permanentes reelaborações que caracterizam a construção do conhecimento científico (MARTINS, 2008, p. 81).

Martins (2008) vai ainda além posicionando a indissociabilidade ensinopesquisa-extensão enquanto "fundamento metodológico do ensino superior" (p.83), devendo ser norteadora de todo o complexo processo de formação dos estudantes. 
Contudo, para que tais premissas se efetivem, é necessário que os projetos e propostas de extensão reflitam sobre suas configurações, bem como acerca da estrutura e dinâmica assumidas para o mesmo, se estas favorecem, ou não, o desenvolvimento de todos os seus membros, sejam eles graduandos, docentes ou comunidade.

Partindo dessas considerações, pretende-se apresentar e analisar a configuração de um projeto de extensão universitária, buscando compreender em que medida a mesma favorece a manutenção do tripé ensino/pesquisa/extensão, enquanto promotor de aprendizados múltiplos aos sujeitos do processo (graduandos, docentes e comunidade), superando ações de mera exposição dos alunos a contextos práticos, em que reproduzem mecanicamente atividades que podem, ou não, futuramente favorecer oportunidades vindouras no mercado de trabalho (MARTINS, 2008). Desta forma pretende-se analisar a estrutura e a dinâmica do projeto em questão, destacando:

- A relação estabelecida entre graduandos, docentes e comunidade, articulada ao tripé ensino/pesquisa/extensão;

- A função das supervisões enquanto espaço formativo;

- A vivência em grupo enquanto espaço de formação para os futuros docentes;

- A adoção da pesquisa-ação na produção do conhecimento.

\section{MARCO TEÓRICO}

A sexualidade, independentemente de sua potencialidade reprodutiva, relaciona-se com a busca do prazer. Trata-se de uma necessidade fundamental dos seres humanos que se manifesta desde o nascimento até a morte, de formas diferentes, a cada etapa do desenvolvimento, envolvendo as dimensões biológica, psíquica e sociocultural. Assim, a sexualidade se constrói pelo sujeito nas e através das relações sociais. Trata-se, portanto, de um processo contínuo, permeado por valores, crenças e de padrões socialmente estabelecidos de feminino e masculino. Como define a Organização Mundial de Saúde (2004): 
A sexualidade é um aspecto central do ser humano durante sua vida e compreende o sexo, identidades e papéis de gênero, orientação sexual, erotismo, prazer, intimidade e reprodução. A sexualidade é vivenciada e expressa em pensamentos, fantasias, desejos, crenças, atitudes, valores, comportamentos, práticas, papeis e relações. Embora a sexualidade possa incluir todas essas dimensões, nem todas elas são sempre vivenciadas ou expressas. A sexualidade é influenciada pela interação de fatores biológicos, psicológicos, sociais, econômicos, políticos, culturais, éticos, legais, históricos, religiosos e espirituais (OMS, 2004).

Faz-se premente o posicionamento da sexualidade no campo dos direitos. Conforme a Organização Mundial de Saúde (2004):

Os direitos sexuais abrangem direitos humanos já reconhecidos por leis nacionais, documentos internacionais sobre direitos humanos e outras declarações consensuais. Isso inclui o direito de toda pessoa, livre de coerção, discriminação e violência, ao seguinte: o mais alto nível de saúde sexual e reprodutiva; educação da sexualidade; respeito à integridade corporal; escolha de parceiro e parceira; decisão de ser ou não sexualmente ativo(a); relações sexuais consensuais; casamento consensual; decisão de ter ou não filhos e quando ter; busca de uma vida sexual satisfatória, segura e prazerosa.

De acordo com Seffner (1998), o ambiente escolar é um local atravessado pela sexualidade e relações de gênero. A escola é um lugar de informação e formação, no qual estão presentes todas as áreas do conhecimento de forma ordenada, em que se constitui um percurso a ser desenvolvido pelo aluno, mas é também promotora de um conjunto amplo de relações sociais e humanas. O mesmo autor refere que a sexualidade é um tema que provoca temores em muitos professores, pois no seu bojo traz uma série de assuntos polêmicos e/ou sentidos como constrangedores: sexo, drogas, orientação sexual e identidade de gênero, promiscuidade, doença, pecado, discriminação, entre outros (SEFFNER, 1998). Devido a esses temores, os professores muitas vezes acabam por disseminar, através de aulas baseadas em uma metodologia eminentemente transmissiva, uma visão reducionista dos assuntos referentes à sexualidade e gênero, pautando-se em uma visão higienista sendo o estudo do mesmo delegado ao campo da Biologia (REIS; RIBEIRO, 2005). Reproduzem-se discursos e práticas heteronormativas, calcadas em uma concepção binária de gênero, que ordena o mundo em dois polos, 
sendo os genitais de nascimento a determinação para a classificação, ordenamento e definição de condutas daquilo que passa a ser compreendido como homem e mulher (SANTOS, 2010).

Conforme aponta Silva (2002), o mais sério erro dos projetos que visam emancipação, promoção de cidadania e transformações de ações dos sujeitos é sua restrição à transmissão de informações e técnicas. Desse modo, mesmo que a informação seja clara, objetiva e adequada aos diferentes tipos de segmentos da população, ela, em si, não garante a sensibilização pessoal ou do coletivo e, portanto, não resulta na incorporação de um novo conhecimento ao cotidiano.

Pensando nisso, a partir de demanda dos licenciandos em Ciências Biológicas, que diagnosticaram que não possuíam subsídios para o enfrentamento do tema sexualidade assim como Ihes era solicitado no cotidiano da escola, é desenvolvido, desde 2005, o Projeto de Extensão SEJu que visa se constituir enquanto um duplo espaço formativo: para os licenciandos participantes e para os jovens da escola pública.

\section{METODOLOGIA}

O presente trabalho adota uma metodologia qualitativa (BOGDAN; BIKLEN, 1994). Foi utilizada como instrumento de coleta de dados a análise documental dos registros realizados pelos docentes coordenadores, ao longo dos nove anos de existência do Projeto de Extensão.

Além dos registros, foram utilizados também como instrumentos de coleta de dados questionários, compostos por questões dissertativas, respondidos por 24 integrantes e ex-integrantes do Projeto em questão, entre os anos de 2005 e 2011. As questões versavam sobre o aspecto formativo do projeto para a futura atuação docente, bem como as possíveis mudanças de concepções, crenças, estereotipias e preconceitos acerca de assuntos referentes ao tema sexualidade.

Os dados foram organizados e analisados a partir do método de análise de conteúdo (BARDIN, 1977). Inicialmente foram identificadas as unidades de registro que posteriormente foram classificadas e agregadas em categorias temáticas. Os dados foram discutidos à luz dos referenciais teóricos que norteiam o estudo. 
Destacamos que os nomes utilizados são fictícios para resguardar o sigilo das fontes.

\section{POR UMA APRESENTAÇÃO E ANÁLISE DO PROCESSO}

Nesse tópico visa-se ultrapassar o caráter descritivo (conscientes de que toda descrição se dá a partir de um limite de olhar), buscando articular elementos de análise dos processos vividos, organizados a partir das seguintes categorias, que foram construídas por alicerce dos objetivos traçados para o presente trabalho: configuração e dinâmica do projeto; relações entre os sujeitos do projeto; o trabalho com/em grupo; a função das supervisões; a pesquisa-ação na produção do conhecimento.

\section{Estrutura e dinâmica do Projeto em questão}

O projeto nasceu a partir da demanda de um grupo de alunos que, após a participação em um evento sobre educação, organizado pelo curso de licenciatura em Ciências Biológicas ao qual pertenciam, em que se sentiram motivados a compor/participar de algo que os aproximasse da comunidade.

Procuraram uma docente para saber das possibilidades existentes e, como resultante desse diálogo, propôs-se a constituição de um Projeto de Extensão com o objetivo principal de trabalhar, através de oficinas, os temas sexualidade e gênero, principalmente junto a jovens de Escolas Públicas do município.

A escolha dos temas pautou-se na experiência de trabalho da docente, no reconhecimento da importância dos mesmos para a comunidade, mas especialmente na lacuna identificada no processo de formação desses alunos que não contemplava adequadamente as discussões acerca da sexualidade e gênero no cotidiano escolar, desafio que certamente enfrentariam na condição de profissionais. Ao longo do processo de constituição, outra docente agregou-se à coordenação.

O trabalho é desenvolvido desde 2005, em Escolas Públicas do município de Jaboticabal. Tem como objetivo trabalhar temas relativos à sexualidade e gênero, junto a adolescentes. Para tanto, são desenvolvidas oficinas, com frequência 
semanal (cerca de doze, no total). Tem-se como objetivos específicos: prover a clarificação de valores, através de um ambiente favorável à reflexão e expressão; fornecer informações sobre doenças sexualmente transmissíveis; possibilitar a subjetivação de informações acerca de sexualidade e DSTs; promover o respeito à diferença e à diversidade sexual e de gênero; possibilitar que o adolescente se sinta responsável por suas escolhas. Além disso, também se pretende a formação de futuros educadores mais capazes para o trabalho com os temas em seu cotidiano pedagógico.

Pauta-se nos pressupostos das metodologias participativas tendo, como ponto de partida para as ações, os sujeitos para os quais as mesmas são direcionadas. Assim, os jovens são entendidos enquanto agentes ao longo de todo o processo, visto que se busca ultrapassar a mera transmissão de informações, possibilitando o desenvolvimento da reflexão e a subjetivação dos conteúdos (SILVA, 2002).

Cada encontro é registrado em diário de campo e discutido em supervisão com as docentes coordenadoras e demais alunos membros do projeto. Assim, a intervenção é construída durante todo o processo, tendo como alicerce as demandas específicas de cada grupo. Além disso, são realizados leituras e estudos de bibliografias pertinentes.

Os trabalhos desenvolvidos pelos universitários nas escolas, com os grupos de adolescentes, envolveram, até o momento cerca de 650 estudantes de escolas estaduais do município e 30 alunos de graduação do curso de Ciências Biológicas da FCAV-UNESP. Os universitários participantes do Projeto de Extensão semanalmente são supervisionados pelas professoras coordenadoras do mesmo. As reuniões se configuram em espaço de estudo e reflexão teórica e ainda em espaço no qual se discutem as metodologias e estratégias que foram utilizadas durante os encontros com os adolescentes e os resultados obtidos, bem como se definem os temas a serem trabalhados nos próximos encontros elaborando novas metodologias.

As oficinas se desenvolvem nas dependências das escolas, com grupos de alunos de diferentes turmas. Cada oficina tem a duração total de duas horas, realizada no contraturno do horário escolar. Cabe ressaltar que os licenciandos são preparados para trabalhar e conduzir o debate em duplas, partindo sempre de 
dúvidas, opiniões e valores dos próprios participantes manifestos em voz alta ou depositadas na 'caixa de dúvidas'.

Inicialmente, os acadêmicos se apresentam, entregam termo de autorização a ser assinado pelos pais e explicam os objetivos dos encontros. Posteriormente, em outro dia, é feita a abertura da oficina pelos licenciandos, as turmas de alunos são divididas em subgrupos menores e é construído o contrato pedagógico de cada subgrupo com a dupla de licenciandos que os acompanhará durante toda a oficina.

Após a elaboração coletiva do contrato pedagógico, dá-se início ao trabalho com os temas que são introduzidos por meio técnicas lúdicas, vivências e dinâmicas de grupo. É importante esclarecer que todas as dinâmicas propostas possuem objetivos definidos que buscam a reflexão e desenvolvimento da condição de análise e posicionamento dos adolescentes. O processo com cada grupo é único, partindo das demandas, dúvidas e conhecimentos prévios dos mesmos. A título de exemplificação, apresenta-se o Quadro 1, em que um processo desenvolvido com um grupo em específico é sintetizado.

Ratifica-se que as discussões empreendidas pelos licenciandos junto ao grupo não se limitam à veiculação de informações de caráter puramente biológico ou preventivo, no que se refere ao controle das DSTs e gravidez indesejada, mas, do contrário, incluem um questionamento mais amplo sobre a sexualidade, gênero e seus valores.

\begin{tabular}{lll}
\hline \multicolumn{1}{c}{ Atividade realizada } & \multicolumn{1}{c}{ Objetivos } \\
\hline Contrato Pedagógico & $\begin{array}{l}\text { Desenvolver ambiente em que os adolescentes se } \\
\text { sintam acolhidos e seguros para as discussões } \\
\text { referentes à sexualidade }\end{array}$ \\
\hline $\begin{array}{l}\text { Levantamento de } \\
\text { expectativas e dúvidas } \\
\text { através da caixa de dúvidas }\end{array}$ & $\begin{array}{l}\text { Identificar temas de maior interesse em sexualidade } \\
\text { e/vidas dos alunos }\end{array}$ \\
$\begin{array}{l}\text { Dinâmicas de apresentação } \\
\text { variadas, dinâmica da batata } \\
\text { quente }\end{array}$ & $\begin{array}{l}\text { Buscar o acolhimento e o entrosamento entre os } \\
\text { membros do grupo }\end{array}$ \\
\hline
\end{tabular}


Dinâmica do rótulo

Dinâmica com massinha de modelar

Dinâmica de desenhos de modelos feminino e masculino pelos alunos em tamanho real; dinâmica da bolsa de menino e bolsa de menina.

\section{Dinâmica de desenhos de} modelos feminino e masculino pelos alunos em tamanho real; dinâmica da bolsa de menino e bolsa de menina, discussão de curta metragens.

Dinâmica da cadeia de Refletir sobre os mitos relacionados à anticoncepção e transmissão, Dinâmica mitos e tabus - jogo 'valores em jogo'

Dinâmica 'A história de
Camila'.

Refletir sobre como estereótipos e interpretações subjetivas interferem na comunicação e percepções que possuímos sobre outra pessoa

Discutir como os participantes percebem os papéis sexuais entre homens e mulheres na sociedade Evidenciando as diferenças entre os papéis sexuais dentro do nosso contexto cultural

Conversar sobre os estereótipos que dificultam a expressão dos adolescentes; conhecer como um "modelo pronto" interfere nos sentimentos e na vivência da sexualidade de homens e mulheres doenças sexualmente transmissíveis (DST)

Refletir sobre a negociação do uso de camisinha com os parceiros, o reconhecimento e a busca de possíveis soluções frente a conflitos no relacionamento, discutir e se posicionar frente a um caso de gravidez na adolescência, bem como de refletir acerca da importância de se planejar uma relação sexual e de fazer contracepção

Dinâmica de cartazes sobre os métodos, dinâmica vestindo a camisinha. Identificar os diferentes métodos contraceptivos e identificar os de uso mais indicado e sua eficácia

Quadro 1 - Atividades realizadas durante as oficinas de sexualidade e objetivos educacionais relacionados às mesmas, em um grupo específico.

Os graduandos, antes de iniciarem o processo de trabalho com os grupos realizam uma formação em que vivenciam as discussões e dinâmicas que possivelmente coordenarão na escola. Os registros dos trabalhos e supervisões também se constituem em fonte de dados a serem estudados e analisados.

Entende-se que a estrutura e a dinâmica do projeto colaboram para o desenvolvimento também dos universitários, visto que não há uma cisão entre o pensar e o executar (BLEGER, 1998). Na medida em que não há um planejamento 
rígido da trajetória dos grupos, os graduandos compõem o processo de planejamento contínuo que só é possível, através da reflexão e análise do caminhar de cada grupo específico, ultrapassando o caráter de mera transmissão de conhecimentos técnicos (MARTINS, 2008).

\title{
RELAÇÃo ENTRE OS SUJEITOS DO PROJETO E O TRABALHO COM/EM GRUPO
}

Prima-se para que os membros que compõem o SEJu também se constituam enquanto um grupo. Em supervisões, os alunos relatavam dificuldades enfrentadas no entendimento e condução do trabalho com grupos, fosse nas escolas, ao longo dos processos de intervenção, fosse entre eles "os sejuanos", como ao longo do tempo passaram a se denominar. Referiam também que era algo que pouco desenvolviam ao longo de sua formação na graduação, na medida em que, em grande parte dos trabalhos que deveriam desenvolver coletivamente, lidavam de forma fragmentada, dividindo tarefas e não tendo uma atuação mais integrada.

Percebiam, então, a experiência no Projeto como uma forma de desenvolvimento desse saber, tão importante na atuação enquanto futuros docentes. Assim afirmou Helena:

\begin{abstract}
As discussões propiciadas em momentos de formação, junto ao preparo de atividades e posterior aplicação na escola e a experiência no contato com os alunos de diversas faixas etárias, promove segurança e entendimento da necessidade em se trabalhar o tema sexualidade com os jovens. [...] antes não conseguia participar efetivamente e nem conduzir discussões, e o trabalho feito em nosso grupo me deu segurança para instigar questionamentos e desenvolver debates de diversos assuntos.
\end{abstract}

Como diz Bleger (1993), o trabalho em grupo oportuniza interações entre os sujeitos, em que, ao mesmo tempo em que esses aprendem, também se constituem como sujeitos do saber. Dessa forma, nos processos de grupo, concomitantemente se aprende e ensina. Como afirma o autor:

O ser humano está integralmente incluído em tudo aquilo em que intervém, de tal maneira que quando existe uma tarefa sem resolver há, ao mesmo tempo, uma tensão ou conflito 
psicológico, e quando é encontrada uma solução para um problema ou tarefa, simultaneamente fica superada uma tensão ou um conflito psicológico (BLEGER, 1993, p. 62).

Assim, o grupo universitário, ao tomar para si, a reflexão acerca dos desafios e tensões que vão se configurando ao longo das oficinas que desenvolvem com os adolescentes, problematiza também suas concepções, posturas e ações, bem como espelha, uns aos outros, questões despertas por aquele trabalho, mas que, até então, não puderam ser reconhecidas pelos sujeitos. Além disso, tem-se a oportunidade de refletir acerca dos processos grupais por um outro prisma, qual seja aquele de se constituir enquanto membro de um grupo que se propõe a trabalhar com outros. Como afirma Joana:

[...] aprendi conviver com pessoas que tem pensamentos diferentes dos meus e mesmo assim conseguir chegar em um acordo para saber o que passar e como passar para os alunos.[...] foi um aprendizado muito grande, que não conseguiria ter se não tivesse ido para a sala de aula, onde as coisas podem acontecer totalmente ao contrário do planejado [...] melhorei muito por causa das dinâmicas na formação e das discussões nas reuniões[...] sei que já melhorei muito, nunca pensei que conseguiria chegar em uma sala de aula e comandar uma dinâmica, mesmo tendo as outras meninas do grupo comigo, e percebi que fui melhorando isso ao longo dos encontros mesmo, cada vez me sentia mais a vontade para falar 0 que pensava, tanto com os alunos como nas reuniões.

Entendemos que o desenvolvimento de condição de trabalhar com grupos só é possível através da atuação refletida, o que inclui a necessidade do estudo dos conhecimentos teóricos, e que, portanto, pressupõe uma relação vivencial. Assim, pressupõem-se a compreensão do conhecimento enquanto um processo de construção contínua, em que as cristalizações apenas reduzem a compreensão e reproduzem as condições sociais postas (MARTINS, 2008). Oportuniza-se, portanto, o questionamento de estereotipias e preconceitos, como afirma Raquel:

Aprendi muito sobre o tema sexualidade, pude mudar vários conceitos errados que apresentava sobre esse tema e quebrar preconceitos que possuía. 
Busca-se uma relação de parceria, para a efetiva construção do conhecimento, entre docentes, graduandos e comunidade, cada qual compreendido como detentor de saberes, mas também capaz de transformações e novos aprendizados. Essa configuração se torna ainda mais premente quando se trabalha com temas de sexualidade e gênero, em que é necessário superar os próprios estereótipos e visões normativas, para que efetivamente sejam construídos espaços de reflexão, subjetivação e clarificação de sentimentos que favoreçam a vivência da sexualidade mais consciente. Como relata Anita:

\begin{abstract}
Antes eu pensava ser uma mulher sem preconceitos pois, aceitava casais homossexuais, pois aceitava, por achar um absurdo qualquer discriminação a cor pele ou estilo de vida. Depois do SEJu eu tive a dimensão de que os preconceitos vão muito além disso, estão em cada pequeno pensamento de intolerância ao diferente. $E$ ainda, não é pelo fato de tolerar e aceitar que necessariamente deixei de ter preconceito. Em verdade me descobri uma mulher com muitos preconceitos e o grupo me ajuda constantemente a questioná-los e, por conseguinte, a lidar com eles.
\end{abstract}

Destaca-se que posturas que negassem os saberes, sentidos e vivências de qualquer dos grupos de sujeitos (universitários, docentes e comunidade), no trabalho com a sexualidade e gênero, reproduziriam normatizações e normalizações, sem oportunizar uma compreensão da sexualidade enquanto um processo contínuo de construção que compõem intimamente nossa identidade. Reproduzir-se-ia, portanto, um modelo higienista e heteronormativo (REIS; RIBEIRO, 2005). Como nos aponta Irene:

O aprendizado adquirido com o grupo proporciona uma visão muito mais ampla sobre a sexualidade e sobre como trabalhá-la em sala de aula [...] através do trabalho com o grupo é possível perceber erros frequentemente cometidos ao se trabalhar sexualidade, como 0 discurso biologizante, e encontrar maneiras mais apropriadas para discutir o tema e conseguir abranger vários aspectos a ele relacionados.

Na medida em que a licencianda manifesta em sua resposta a compreensão de que o seu trabalho na escola, frente a temas associados à sexualidade, é 
também 0 de problematizar, levantar questionamentos e ampliar o leque de conhecimentos e de opções para que o aluno escolha seu caminho, e não o de fornecer respostas prontas e acabadas, respostas associadas apenas a visão anátomo fisiológica da sexualidade, depreendemos que a mesma desenvolveu um saber disciplinar necessário para se trabalhar o tema transversal Orientação Sexual em sala de aula.

Percebe-se que a licencianda compreendeu que o seu trabalho na escola, frente a temas associados à sexualidade, é também o de problematizar, levantar questionamentos, ampliar o leque de conhecimentos e de opções para que $o$ aluno escolha seu caminho, e não o de fornecer respostas prontas e acabadas, respostas associadas apenas a visão hegemônica da sexualidade e gênero. Nesse sentido, depreendemos que desenvolveu-se um saber disciplinar necessário para se trabalhar o tema transversal Orientação Sexual em sala de aula.

De acordo Britzman (2000):

A cultura da escola faz com que respostas estáveis sejam esperadas e que o ensino de fatos seja mais importante do que a compreensão de questões íntimas. Além disso, nessa cultura, modos autoritários de interação social impedem a possibilidade de novas questões e não estimulam o desenvolvimento de uma curiosidade que possa levar professores e estudantes a direções que poderiam se mostrar surpreendentes. Tudo isso faz com que as questões da sexualidade sejam relegadas ao espaço das respostas certas ou erradas (BRITZMAN, 2000, p. 83).

É essencial que o futuro professor aprenda que o trabalho em sala de aula com o tema sexualidade precisa ser desenvolvido de uma forma dialógica, compreendendo que o ser humano é muito mais do que um corpo com necessidades físicas. É, por sua vez, dotado de emoções e está inserido em um contexto sócio-cultural, onde atitudes e comportamentos são moldados pelas constantes mudanças sociais e culturais. Como refere Olga:

Aprendi a partir dos conceitos prévios de cada turma, a lidar com os assuntos de várias maneiras diferentes, olhar de vários ângulos, não dar minha opinião pessoal e mostrar todas as variáveis, responder "não sei" e entregar a resposta no próximo encontro, entender que cada aluno tem uma vivência e um conceito pessoal, explicar a 
mesma coisa de várias maneiras diferentes dependendo da faixa etária e de cada turma[...].

\section{A FUNÇÃO DAS SUPERVISÕES}

Semanalmente ocorrem supervisões, compostas pelos graduandos e as duas professoras coordenadoras do projeto.

Como afirmam Fernandes e Barletta (2004, p. 16) "O termo supervisão, segundo vários dicionários, refere-se a dirigir, orientar, inspecionar", tendo a sua origem na relação hierárquica e de fiscalização entre mestres e aprendizes nas corporações de ofício na idade Média.

Contudo, tomamos o momento da supervisão como um possível encontro entre docentes e universitários, com seus olhares distintos, na busca da construção de uma visão, o mais complexa possível, acerca das vivências com os grupos. Assim, não se trata de negar a importância da experiência e dos conhecimentos dos docentes coordenadores, mas sim de demarcar a compreensão de que não se pode avançar no conhecimento a partir de uma relação em que uma das partes funciona como o "super visor", aquele que está posto para controlar e fiscalizar o andamento de dado trabalho, como afirmam os autores:

A supervisão é uma experiência muito rica na qual tanto o supervisor como os supervisionados podem compartilhar suas ideias $e$ conhecimentos. É um processo um tanto longo, difícil, complexo e adorável, pois se percebe o grupo crescer como um todo assim como seus participantes em particular (FERNANDES; BARLETTA, 2004, p.16).

Portanto, talvez o termo mais adequado, para descrever esse processo, fosse "atervisão", não uma compreensão/visão que é superior, mas outra visão que colabora para o desenvolvimento de universitários, professores e comunidade.

É no momento da supervisão que cada encontro com os adolescentes é apresentado, refletido e, a partir das percepções dos universitários/coordenadores, demais membros do grupo de supervisão e dúvidas postas pelos jovens em caixinhas destinadas para tal, o próximo encontro com o grupo é planejado. Segundo Jalili: 
Pude identificar que cada turma é única e que não podia aplicar a mesma dinâmica e esperar que esta seja significativa para todas[...]

Ao longo dos processos de supervisão é possível acompanhar a reconstrução de sentidos trazidos por universitários e docentes, bem como o reconhecimento e a desconstrução de preconceitos e estereótipos. Lúcia afirma:

Os encontros (de supervisão) nos levam a refletir e a rever nossas concepções acerca das coisas" [...]a participação no projeto me fez entender melhor questões que antes não compreendia muito bem, e a perceber que existe uma diversidade muito grande de pessoas e de gostos e que isso é normal.

Entende-se que o espaço da supervisão é, portanto, privilegiado para construção do conhecimento e formação dos universitários, em uma perspectiva em que se prima pela indissociabilidade da teoria e da prática.

\section{A PESQUISA-AÇÃO NA PRODUÇÃO DO CONHECIMENTO}

No projeto em questão, intervenção e pesquisa também não são compreendidas de forma estanque. Afinal, o encontro com o real é um convite constante à busca de uma compreensão sistemática, organizada e aprofundada. Dizemos, portanto, da teoria que transforma o real, mas também a si constantemente quando confrontada com o mesmo. Assim, adota-se a pesquisaação que, conforme Tripp (2005, p. 463), compreende é:

[...] uma variedade de investigação-ação, na qual se empregam técnicas de pesquisa, de qualidade suficiente para enfrentar a crítica dos pares na universidade, para informar o planejamento e a avaliação das melhoras obtidas.

Para tanto, adolescentes e responsáveis são esclarecidos acerca desse caráter do projeto, só compondo os resultados de pesquisa aqueles que concordam formalmente, através da assinatura de um termo de consentimento livre e esclarecido. 
Entende-se essa perspectiva como também potencial de ruptura com visões estereotipadas e medicalizantes da sexualidade e da adolescência. Isso porque a pesquisa-ação permite aos universitários, em formação, a compreensão conhecimento enquanto uma construção social, que se dá na relação da realidade com os pesquisadores. Marcela pontua:

Aprendi que o conhecimento não é pronto, vamos construindo com a nossa ação.

Ao buscar compreender as configurações distintas dos grupos trabalhados, lança-se luz na diversidade que não pode ser escalonada, ou representada com justiça por padrões pré-fixados. A realidade pode revelar-se, assim, múltipla, polifônica e aberta a olhares muito distintos.

Visa-se ainda, dessa forma, chegar à indicação de Martins (2008) daquilo que, na compreensão dela, deve ser "fundamento metodológico do ensino superior" (p. 83): a indissociabilidade ensino/pesquisa/extensão.

\section{CONSIDERAÇÕES FINAIS}

O projeto em questão sustenta-se por pilares alicerçados na compreensão de sexualidade que está em sua base, sendo esta um processo contínuo de construção humana, muito além da prática sexual, mas que constitui a própria identidade do sujeito através das relações que estabelece com o outro, com o próprio corpo e com o prazer. Assim, visa-se favorecer processos formativos que rompam com visões estereotipadas e biologizantes da sexualidade, superando a visão higienista que predomina nos processos educacionais escolares.

Para tanto, pensou-se um projeto que favorecesse o desenvolvimento dessa perspectiva acerca da sexualidade, bem como a indissociabilidade ensino/pesquisa/extensão fundamentassem sua própria estrutura e dinâmica. Temse como princípios fundantes nesse projeto:

- A relação estabelecida entre graduandos, docentes e comunidade, articulada ao tripé ensino/pesquisa/extensão; 
- As supervisões enquanto espaço formativo;

- A vivência em grupo enquanto espaço de formação para os futuros docentes;

- A adoção da pesquisa-ação na produção do conhecimento.

A experiência com o projeto indica para a importância da perspectiva metodológica que assume o processo de ensino/aprendizagem, no ensino superior, fundamentado no tripé ensino/pesquisa/extensão. Trata-se de uma condição de construção contínua de conhecimento entre parceiros, que ocupam funções distintas, contudo não subjugadas. Assim, favorece-se a emancipação dos diferentes sujeitos, na medida em que são compreendidos como dotados de saberes, agentes no processo de construção de conhecimentos seus e de outros, que também são entendidos enquanto construtores, afinal: "ninguém educa ninguém, ninguém a si mesmo, os homens se educam entre si, mediatizados pelo mundo" (FREIRE, 1987, p.39).

Aprender a trabalhar com/em grupos, propicia a vivência que pode ser problematizada, refletida e compreendida. Isso colabora para o desenvolvimento de saberes acerca de dinâmica e manejo de grupos que não seriam possíveis fora dos universos experiencial e teórico articulados em uma unidade.

O trabalho com grupos também favorece a circularidade de papéis entre os diversos componentes do mesmo (sejam eles da universidade ou da comunidade). Assim, hora se ocupa a posição de quem aprende e hora de sujeito do saber. Nessa configuração, todos são representados como capazes e, dessa forma, sujeitos no processo de construção de seus conhecimentos e ações. Destarte, podem-se questionar sentidos, estereótipos, preconceitos e ações.

Destaca-se, também, que o espaço das supervisões mostrou-se bastante significativo para o processo de formação do coletivo.

O conhecimento compreendido enquanto um processo de construção contínua, em uma relação dialética teoria/prática, oportuniza a ruptura com conceitos institucionalizados, normatizações e normalizações, em que a sexualidade é reduzida a uma compreensão biologicista e heteronormativa. Assim, entende-se a pesquisa-ação enquanto um recurso teórico-metodológico importante. 
Vale a pena ainda registrar as principais dificuldades enfrentadas, pelo Projeto, ao longo desses anos de trabalho. A primeira delas se refere ao desprestigio da Extensão dentro da configuração produtivista da Universidade, em que a premência de publicações sombreia todo o trabalho acadêmico que, conforme pontuado, deve sustentar-se pelo tripé ensino, pesquisa e extensão, sendo estes indissociáveis.

As concepções produtivista e individualista também são introjetadas pelos alunos, o que dificulta a adesão aos projetos de extensão, que necessitam de horas de dedicação de trabalho, além de um processo inicial de formação que dura um semestre.

Outro elemento dificultador é a representação da atuação em Extensão Universitária a partir do prisma de "atuação social caridosa", em que a comunidade é percebida como desprovida de saberes verdadeiros e os universitários como aqueles que "possuem o saber científico" e, portanto correto, sendo capazes de prescrever ações e condutas mais adequadas para aqueles que estão para serem ensinados. A manutenção dessa concepção, seja por parte de qual dos agentes, impede as trocas reciprocas e os efetivos processos de construção de saberes que, em nenhuma medida, são unilaterais.

$\mathrm{Na}$ relação com as escolas, a negociação de espaços em que se possa trabalhar com os jovens sexualidade e gênero a partir do prisma dos direitos e da promoção do respeito à diversidade também comparece enquanto um desafio, especialmente em tempos como os nossos em que crescem as manifestações religiosas de cunho fundamentalista e contrárias aos direitos sexuais.

Portanto, existe um caminho trilhado, mas sabemos que há muito a ser construído adiante.

\section{REFERÊNCIAS BIBLIOGRÁFICAS}

AFONSO, L. Oficinas em dinâmica de grupo: um método de intervenção psicossocial. Belo Horizonte: Edições do Campo Social, 2002. p. 11-59.

BARDIN, L. Análise de Conteúdo. Lisboa: Edições 70, 1977. 
BLEGER, J. Temas de Psicologia: entrevistas e grupos. São Paulo: Martins Fontes, 1993.

BOGDAN, R.; BIKLEN, S. Investigação qualitativa em educação. Porto: Porto Editora, 1994.

BRITZMAN, D. Curiosidade, sexualidade e currículo. In. LOURO, G.L. (org.). O corpo educado: pedagogias da sexualidade. 2. Ed. Belo Horizonte: Autêntica, 2000. p. 52-83.

FERNANDES, B. S.; BARLETTA, J. B. A supervisão, o supervisor e os supervisionandos. Revista SPAGESP, Ribeirão Preto, v. 5, n.

5, dez. 2004. Disponível em $<$ http://pepsic.bvsalud.org/scielo.php?script=sci arttext\&pid=S167729702004000100004\&lng=pt\&nrm=iso >. Acesso em: 11 maio 2013.

FREIRE, P. Pedagogia do oprimido. 17. Ed. Rio de Janeiro: Paz e Terra, 1987.

MARTINS, L. M. Indissociabilidade ensino-pesquisa-extensão como fundamento metodológico da construção do conhecimento na Universidade. In. PINHO, S. Z. Oficinas de Estudos Pedagógicos: Reflexões sobre a prática do Ensino Superior. São Paulo: Cultura Acadêmica; Universidade Estadual Paulista; Pró Reitoria de Graduação, 2008. p. 73-85.

REIS, G. V.; RIBEIRO, P. R. M. Sexualidade e educação escolar: algumas reflexões sobre orientação sexual na escola. In: Bortolozzi, A. C.; Maia, A. F. (orgs.). Sexualidade e infância. Bauru: FC/Unesp, Cecenca. 2005. v. 1. p. 37-46. (Série Cadernos Cecenca).

SANTOS, P. R. Desejos, conflitos e preconceitos na constituição de uma travesti no mundo da prostituição. Revista Latino-Americana de Geografia e Gênero, Ponta Grossa, v. 1, n. 1. p. 39-48, 2010.

SEFFNER, F. Aids \& Escola. In: Meyer, D. E. E. (org.). Saúde e Sexualidade na Escola. Porto Alegre: Mediação. 1998. p.125-143.

SILVA, R. C. Metodologias Participativas para Trabalhos de Promoção de Saúde e Cidadania. São Paulo: Vetor. 2002.

TRIPP, D. Pesquisa-ação: uma introdução metodológica. Educação e Pesquisa, São Paulo, v. 31, n. 3, dez. 2005. Disponível em $<$ http://www.scielo.br/scielo.php?script=sci arttext\&pid=S1517-

97022005000300009\&lng=pt\&nrm=iso >. Acesso em : 11 maio 2013. 